\title{
ADOPTION OF HIGH FRAME RATE LIVE-ACTION VIDEO CONTENT ON SOCIAL MEDIA PLATFORMS
}

by

Vibhushan Soundrarajah

\author{
A MRP \\ presented to Ryerson University \\ in partial fulfillment of the \\ requirements for the degree of \\ Master of Digital Media \\ In the Program of \\ Digital Media
}

Toronto, Ontario, Canada, 2017

C) Vibhushan Soundrarajah, 2017 
Author's Declaration for Electronic Submission of a MRP

I hereby declare that I am the sole author of this MRP. This is a true copy of the MRP, including any required final revisions.

I authorize Ryerson University to lend this MRP to other institutions or individuals for the purpose of scholarly research.

I further authorize Ryerson University to reproduce this MRP by photocopying or by other means, in total or in part, at the request of other institutions or individuals for the purpose of scholarly research.

I understand that my MRP may be made electronically available to the public.

Vib Soundrarajah 


\title{
ADOPTION OF HIGH FRAME RATE LIVE-ACTION VIDEO CONTENT ON SOCIAL MEDIA PLATFORMS

\author{
Ryerson University \\ Vibhushan Soundrarajah \\ Master of Digital Media, 2017
}

\begin{abstract}
New cinema technology has always been dictated by hollywood studios and theater exhibitions. With emergence of video streaming technology and smart display availability to the mass population, cinema technology no longer needs to overcome the approval made by studios and exhibitors.

High frame rate is an emerging technology that has the ability to enhance realism and temporal resolution in the production process. This technology is supported by various social video streaming platforms and allows users to experience high frame video. Though this technology is available and accessible, this project assesses the value and adoption of 60 frames per second video content versus the standard 24 frames per second.
\end{abstract}




\section{TABLE OF CONTENTS}

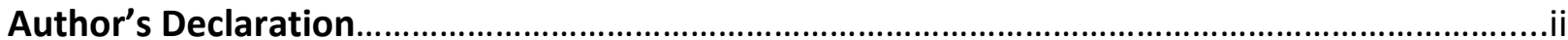

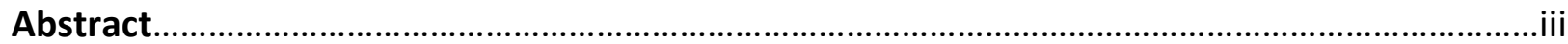

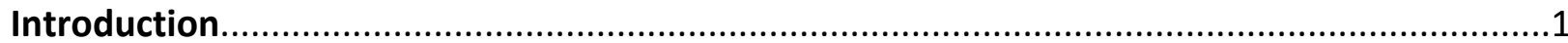

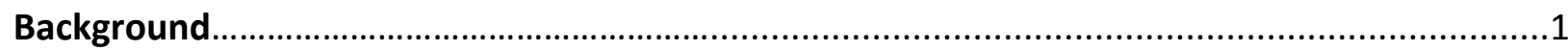

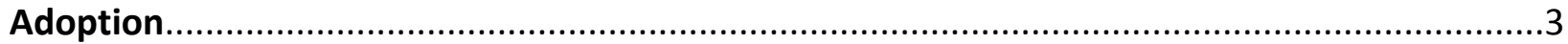

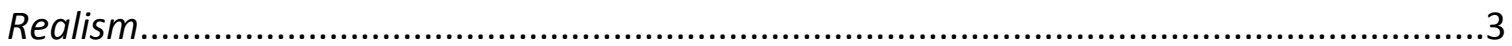

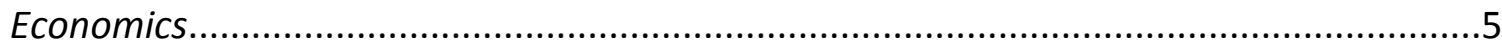

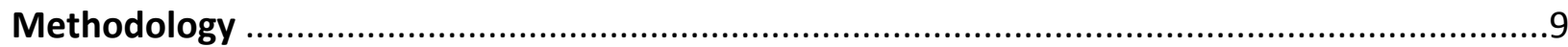

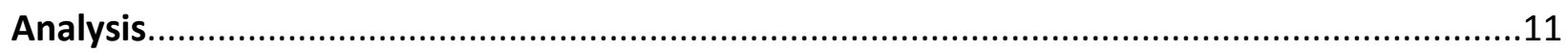

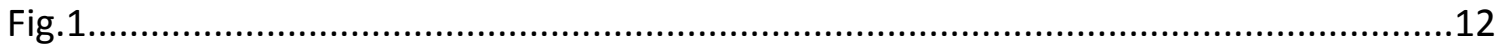

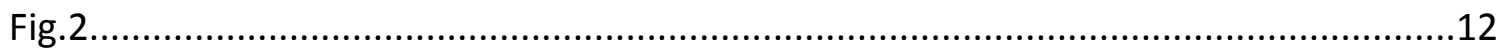

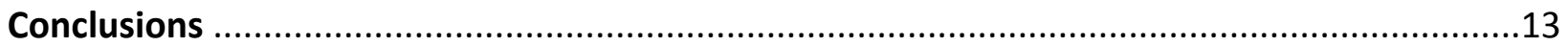

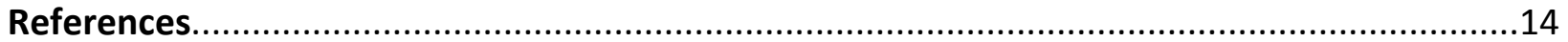




\section{Introduction}

The way we consume video content has changed drastically over a very short span of time. Incentive for people to watch films at the movie theatre have decreased with the emergence of video platforms such as Netflix, Amazon Prime Video, Youtube and Vimeo. With the growth in smartphone and tablet usage, content has become more. Due to new distribution methods, new cinema and video technologies can be discovered and adopted beyond the theatre exhibition. As spatial resolution technology peaks at 3840x2160 pixels, temporal resolution in the form of high frame rate can become the next innovation to enhance the way content is experienced in movie theatres and social platforms. Currently there are only two big budget films made at a high frame rate, which include The Hobbit and Billy Lynn's Long Halftime Walk, with the addition of James Cameran's Avatar sequels that are in production. As filmmakers and studios debate the adoption of creating films in high frame rate, it will be important for online distribution platforms like Netflix,Amazon Prime Video, Youtube, and Vimeo to see how receptive people are to high frame rate video content viewed primarily on mobile devices, and whether this technology can enhance these platforms further. To study this concept, this project will look back on how previous cinematic innovations were adopted through the course of time. I will also create a short film that has been captured, edited and played back in both 60 frames per second and 24 frames per seconds, which will then be released to Vimeo to gather analytical measurements.

\section{Background}


High frame rate video content has the potential to be the next technological advancement in the way people consume video and film. High frame rate refers to the capture and projection at rates higher than the traditional 24 frames per second (Wilcox, 2015). High frame rate in theory improves the quality of motion portrayed in movies and helps avoid motion blur, judder, and other undesirable artefacts however there are limited empirical studies that prove this is true (Wilcox, 2015). However, with the rise in accessibility and affordability of high frame rate video capture and playback through mirrorless cameras and social platforms, people have the opportunity to create and view an abundance of content in high frame rate. It is rare for a new innovations to have the technical infrastructure in place to support its adoption, however in the case of high frame rate, most of this infrastructure is available in both theatre exhibitions and online. With that being said it is important to explore whether people prefer to see high frame rate or even notice a qualitative differences with a traditional 24 frame rate.

The Hobbit Trilogy was the first film to ambitiously take on the challenge of capturing and projecting in high frame rate. The director of the trilogy, Peter Jackson promised that high frame rate, "would effectively eradicate the cinematic 'fourth wall' and greatly enhance viewers' sense of immersion" (Michele, 2017). However based on empirical research, the audience were divided on the value and effects of a high frame rate technology (Michele, 2017). Adoption to anything new generally takes time and must overcome an initial resistance in order to be ubiquitous. Beyond overcoming resistance and time, this paper will explore how technological innovations in cinema have been adopted in the past. 


\section{Adoption}

High frame rate has the potential to become next technological advancement in pushing video and film content to greater heights. To truly evaluate if this technology can be adopted by filmmakers, content creators, audiences, studios, and exhibitors, it will be important to study how previous technological innovations in the industry influenced adoption. The shifts in technology that will studied are silent to sound, black-and-white to colour, analogue to digital cinema, and finally 2-D to stereo 3-D. By exploring the historical transition of these technologies it will be evident that there is a pattern of common factors that contribute to their adoption of these technologies. It will be evident that these factors are, meant to realize cinematic realism and economic profitability for stakeholders.

Realism

Achieving greater realism has always been an objective for content creators and filmmakers. This concept helped push the cinematic experience forward in the transition from silents films to talkies in the late 1920's. By adding synchronized sound to films, filmmakers were able to gain complete creative control in the sound design of their art as the technology was able to replace live orchestras that would usually support a silent film from the side of the exhibition. (Daniela, 2017). This technology integrated another sensory layer to what was once solely a visual experience. Introducing dialogue from actors allowed for greater realism and audience connection to the screen which made adoption an easy transition to talkies. This is evident as Hollywood adopted to sound in the span of 3 years and by the end of 1929, major studios had ceased productions of silent films entirely (Gil, 2012). 
Even though the concept of achieving realism helps build the case for shifts in technology, it is not always adopted easily. This is evident in the transition from black-andwhite to color as the adoption process took 30 years (Gil, 2012). Economical and technological limitations were pivotal factors in delaying adoption. In this example however another rejecting factor for limited adoption was that the audience did not favour colour for realism.

Hollywood's rapid conversion to color was also impeded by the popularity of genres that were not enhanced by color. While adventures and musicals were enhanced by color's association with fantasy, comedies and dramas, which comprised more than 60 percent of the major studios' output between 1940 and 1959, benefited more from black-andwhite's association with realism (Gil, 2012).

Though it would seem that color would enhance the notion of realism in the film medium, the surrounding supporting technologies were still not adequate enough to provide an overall better experience than what a black-and-white picture was providing. To overcome these issues, improvements in art direction and set design were critical for the transition to be successful as color opens up flaws that were previously hidden black-and-white. This adoption hurdle is something that high frame rate technology currently faces as well. Generally people are satisfied with 24 frames per second and don't mind the motion blur it creates. The Hobbit which was filmed in 48 frames per second had many audiences and critics claiming the experience felt like they were on the film set in person thus losing all the magic and illusions of the movie (McGregor, 2017). High frame rate at a technical level produces a more realistic and sharper image, it faces the problem of being too real, much as color was at first. James Cameron who will also be filming in high frame rate for the upcoming Avatar sequels, claims 
that 3D shows you the window to reality whereas high frame rate takes the glass out the window (McGregor, 2017). Though high frame rate is supposed to be a cleaner and a more honest capture of the action in a scene with the artifacts of motion blur removed, it is still perceived to be more disturbing than impressive (Engber 2016). Realism caused by high frame further exposes unbelievability in traditional visual effects scenes as exposed in the Hobbit. Significant viewers experienced this undermining suspension of disbelief and felt the effects were distracting, unconvincing, and poor quality based on a research study (Michele, 2017).

The key problem regarding realism and high frame rate in cinema is that on a Hollywood set there are so many elements that are not real. From artificial props, green screens, and cheap set design flaws are all exposed as the audience is able to absorb more information per second than the traditional 24 frames per second. To make the adoption to high frame rate happen, all these production components will need to transition and adopt to the format, similar to how cinema adapted when sound and color were introduced. Currently travel vlogs captured in high frame rate are getting praised for realism. Since the content is all natural showing real elements, people, and things in action, people are able to appreciate the technology, clarity and realism high frame rate offers (McGregor, 2017). This builds that case that maybe hollywood films have to make massive infrastructure and procedural changes in their filmmaking process to support high frame rate, however high frame rate technology appears to have a platform in more natural forms of content creation such as vlogs and documentaries.

\section{Economics}


Economic interest and profitability for Hollywood studios are primary drivers for technological shifts in the industry. As mentioned before, the lack of realism in the early colour films was a major factor for the 30 year adoption of the technology, however the expensive nature of creating colour films was a pivotal element as well. In the 1950's a cheaper color film stock was introduced that helped color film productions to rise $73 \%$, however the economical results showed weak returns compared to black and white films resulting in a $25 \%$ decline in production shortly after (Gil, 2012). It is evident that studios reverted back to the more familiar and stable technology that was generating the most optimized profitability. Not only was colour film stock expensive but so were the production practices that needed to be changed to support the new format. The cost of production increased significantly as lighting for colour accumulated technical challenges because natural light varied at different hours of the day (Gil, 2012). These newly exposed flaws are expensive and hinder the ambitions of studios that want adopt the new technologies. This is very much the same problem high frame rate currently faces. High frame rate films like The Hobbit faced similar technological issues enforcing the need to change traditional production practices to support high frame rate capture. Just as traditional lighting was problematic in the transition to colour films, computer graphics are also seen to be troublesome with the introduction of high frame rate in the example of The Hobbit. It is claimed that, "with the use of HFR, it evidently outran the current capacity of CGI to believably replicate reality and so undermined the films' perceived (seamlessly layered) realism" (Michelle, 2017). Visual effects budgets are already exponentially increased as render cost and time are doubled in 48 frames per second. This means that visual effects budgets will need to be further increased as traditional CGI practices in 24 frames per second are not 
passable at 48 frames per second. As a result additional costs in R\&D, and look development talent will need to be arranged, which as a result will make the case for adopting to high frame rate more challenging for studios from an economical perspective.

In the economical aspect, it is obviously an obstacle in adopting new technologies, however it will be evident that it is the threat of competitive markets that force studios to accept the additional costs and support the adoption of technologies. It was simply the threat of television and colour broadcasting that nudged film studios to push colour film 30 years after its introduction.

Since networks were eager to fill their programming schedules with color and did not want black-and-white movies, the switch to color broadcasting strongly favored the financing of color features. The new market for color features, which transformed television from a substitute to a complement for color movies, lead to the rapid demise of black-and-white film. Between 1965 and 1967, the share of color movies jumped from 59 to 88 percent; by 1970, the share was 94 percent (Gil, 2012).

It is evident that it was the threat and influence of the television industry that assisted in the $94 \%$ in adoption within the span of 5 years, even though the technology was available 30 years prior. This concept of threat from other markets is what also helped push the transition from analogue to digital cinema as well.

The US studios find themselves challenged by a new generation of entrepreneurs; armed with a combination of ever more affordable filmmaking tools, widening access to broadband networks and mobile communication devices operating on digital platforms. 
Such profound change in the way entertainment is being consumed across the globe has created a potential 'tipping point' in the movie business (Culking, 2008).

Digital cameras and post production software were becoming more accessible and affordable changing the traditional analogue production workflow. The internet was also growing in the role as a content distributor resulting in studios and theatre exhibitors to once again feel threatened. In order to support these changes and compete with the internet, studios were once again forced to adapt to digital cinema capture and projection methods. It was ultimately the threat of the internet that enforced studios to finance the cost of implementing digital projection within cinema theatres. Since there would be no difference visually in the cinema experience for audiences, exhibitors were unable to justify the cost of adapting to digital projectors, forcing studios to pay the price. Though Hollywood and theatre exhibitors made initiatives to support the digital transition, they faced increasing competition from the rise in video streaming via Netflix, tablets, and home entertainment systems (Elaesser, 2013). There were dramatic drops in DVD sales, forcing them to succumb to investing in new equipment to promote theatre attendance (Elaesser, 2013). The technology introduced was stereo 3-D.

Stereo 3-D generates more visual artifacts and an overall darker image on the screen due to the polarizing lens in 3-D glasses. It is evident that studios forced the adoption to stereo 3-D in order combat the internet by providing a visual enhancement that can only be experienced in a theatre venue while sacrificing the quality of the overall picture. In 2010 it was also reported by industry commentators that the introduction of stereo 3-D was a strategy to force theaters to adopt and fund digital projection (Elaesser, 2013). This reveals studios have once again introduced a new technology to differentiate themselves from competing markets and cleverly 
used stereo 3-D as a means of justification to transfer costs of digital projection back to theatre venues.

It is clear the history of cinema that technological innovations were adopted achieve realism in the picture, generate maximized profitability for studios, and to differentiate from competing markets. For high frame rate to be accepted as a standard in cinema technology, studios must see economical benefit to aid the transition. However with the flaws evident with high frame rate in CGI heavy films, there is a better probability for high frame rate to achieve appreciation and adoption via social media. Social media video players such YouTube and Vimeo now support high frame rate playback and affordable high frame rate camera are very accessible, which allows content creators and audiences to experience quality high frame rate without technical barriers. In order to test the success of high frame rate technology, a short realistic live action film will be created and released on various social channels. Using social media analytics and measurement tools the success of high frame rate will be determined.

\section{Methodology}

Empirical data proves that people feel high frame rate technology produces better quality than the traditional frame rate of 24 . However in this research project, the goal is to see how receptive people are to high frame rate content on social media video players that can be viewed on various displays such as computers, tablets, and smartphones. Since the majority of social media users consist of a younger demographic who have greater exposure to high frame rate content such as videogames and virtual reality, it can be hypothesized that high frame rate video will be more receptive than 24 frames per second. 
To be able to study this hypothesis I will be conducting a research experiment in the form of creating a short film. The short film will be produced with a micro budget, as the intended final output would be designed for social which will generally be viewed on smaller than usual screens. The film will be captured using the Sony A7S Mark II camera which has the ability to film up to 120 frames per second at a resolution of $1920 \times 1080$ pixels. This short film will be exported to two versions consisting of one being in 24 frames per second and one being 60 frames per second. There are 3 methods to shoot the film in multiple frame rates. The first option would be to film every scene twice in 24 and 60 frames per second. The problem with this option is that the final output will not be identical as variability will increase between takes. The second option would be to get a second camera mounted beside or on top of the primary camera. Both cameras will film the exact scene however in different frame rates. The problem with this option is the fact that both cameras cannot hold the exact same position resulting in variability between the two films. The final option which is the most beneficial, is to film the scenes in 60 frames per second with one camera and convert the footage to 24 frames per second in post production. This way there is only one take of all the scenes allowing the 24 and 60 frames per second versions to be identical. Whenever the film requires slow motion, I will shoot the film at 120 frames per second to get 50 percent slow motion at 60 frames per second timeline. To get the same result in the 24 frames per second timeline I will convert the 120 frames per second capture to 48 frames per second to achieve the 50 percent slow motion effect. The two edited and exported versions will then be released on Vimeo. After the span of 2 weeks, data analytics from Vimeo will be collected, analyzed, and interpreted to determine how the two versions of the film were received. 


\section{Analysis}

Based on the results of the analytics represented by Vimeo on both versions of the films, it clearly articulates that the 60 frames per second version proved to be more successful. At 60 frames per second version resulted in total of 42 plays, 13 finishes, with a total average of $68 \%$ of watched content was achieved. These results are significantly greater than the 19 plays, 5 finishes and $62 \%$ average of watched content that the 24 frames per second film generated. This is further clarified from a viewer who commented on the vimeo page stating, "60fps is perplexing objectively, it's smoother and more akin to how we see in reality, and yet it still is a bit jarring. Compared to the $24 \mathrm{fps}$ version, this one takes a bit more time to 'get into', if that makes sense." Based on this comment it is evident that this specific person supports Wilcox's (2015) empirical research in that it is smoother and closer to reality. It also supports the concept of realism as a primary influencer in past cinema innovation adoption. The viewer of this comment states, "it takes a bit more time to get used to" which is evident that there is a clear difference between the two frame rates. The unique look of the film is something that can be naturally adopted and transitioned by viewers as the production and consumption of high frame rate content increases. 
Figure 1

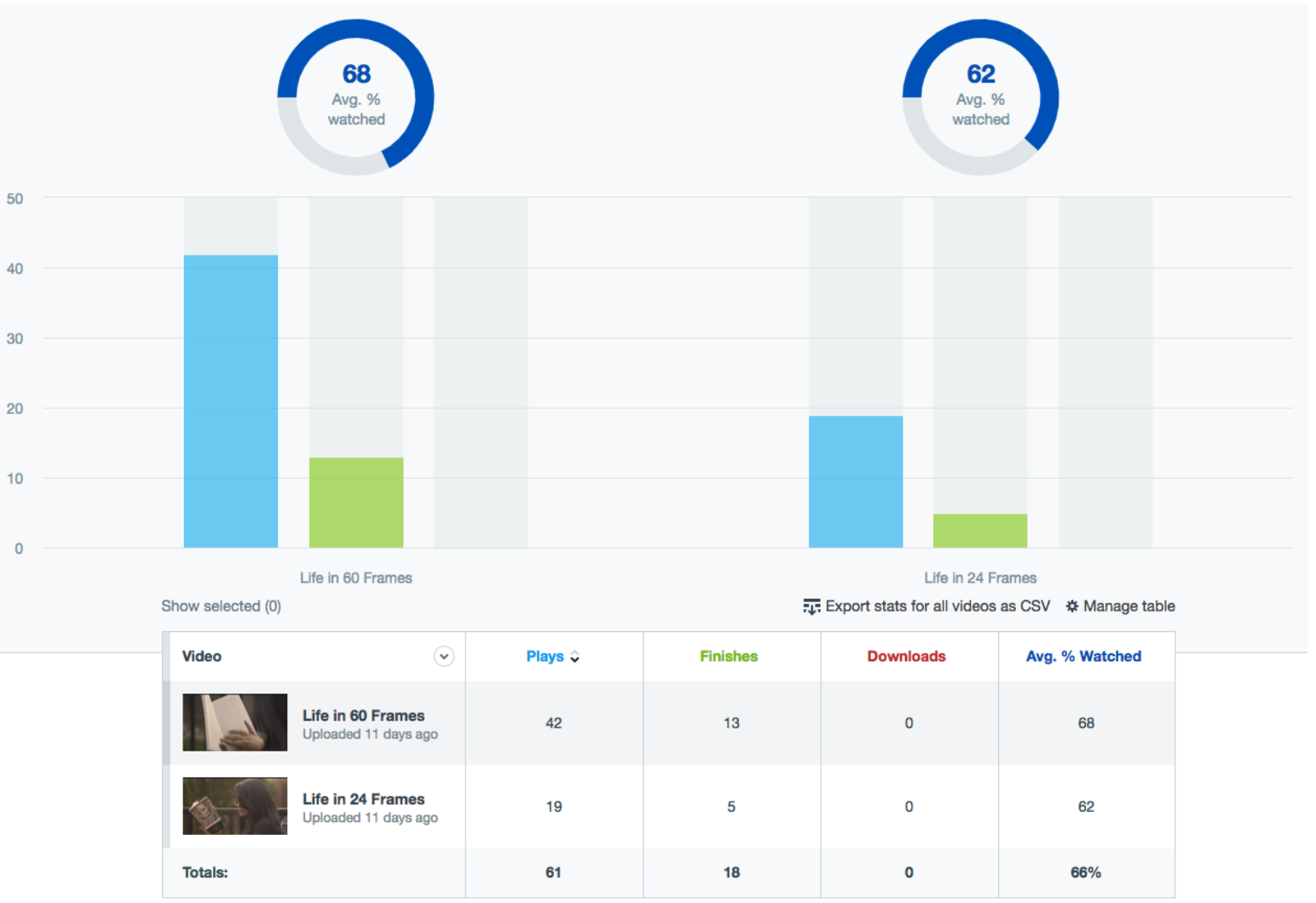

Figure 2

\section{Comment}

\section{Nathan Christie 3 weeks ago}

$60 f p s$ is perplexing--objectively, it's smoother and more akin to how we see in reality, and yet it still is a bit jarring. Compared to the $24 \mathrm{fps}$ version, this one takes a bit more time to "get into", if that makes sense. 


\section{Conclusion}

The perceptual difference in high frame content is clearly evident when compared to the traditional 24 frames per second. From this experimental project it is also evident that the same content filmed in 60 frames per second generated more positive analytics on Vimeo. However through the course of this experiment there are several variable errors that need be factored. Some of these variables include a 24 frames per second film that is not captured in 24 frames natively, delay in release between the 2 films on Vimeo, and use of a small sample size for analytics. To limit the variability of this project it is recommended to use a dual camera rig to use two separate cameras to capture the two frame rates natively. A better social media solution can be implemented so that the two films can be release at the same moment and time. To increase the sample size of this project it would be ideal to explore other social media channels other than Vimeo to gain a better reach. It would also be interesting to further explore the relationships other social media platforms such as Youtube and Facebook have regarding a user's consumption of content.

High frame rate video content on social media has great potential on social media to provide viewers a greater sense of realism. However choosing high frame rate and realism will come at the price of sacrificing the traditional "cinematic look" with heavy motion blur. Differences in limited motion blur and heightened realism will be something that viewers will need to slowly adjust from the transition from a lifetime of experiencing 24 frames per second content. This can easily be achieved by interacting and consuming with more high frame rate content. 


\section{References}

Culkin, N., Morawetz, N., \& Randle, K. (2008). Digital Cinema as Disruptive Technology. Information Communication Technologies and Emerging Business Strategies. doi:10.4018/9781599042343.ch009

Daniela, D. (n.d.). The Advent of Sound: 1927-1930. Retrieved September 08, 2017 , from http://www.cinecollage.net/advent-of-sound.html

Elsaesser, T. (2013). The "Return" of 3-D: On Some of the Logics and Genealogies of the Image in the Twenty-First Century. Critical Inquiry,39(2), 217-246. doi:10.1086/668523

Engber, D. (2016, October 20). Ang Lee Has Made the Most Realistic-Looking Movie Ever. It's Unwatchable. Retrieved September 08, 2017, from http://www.slate.com/articles/arts/movies/2016/10/billy_lynn_s_long_halftime _walk_looks_fantastic_it_s_also_unwatchable.html

Gil, R., \& Lampe, R. (2012). The Adoption of New Technologies: Understanding Hollywood?S (Slow) Conversion to Color, 1940-70. SSRN Electronic Journal. doi:10.2139/ssrn.2176802

McGregor, L. (2017, June 26). Is HFR The Future of Travel Videos? - The Beat: A Blog by ... Retrieved September 8,2017, from https://www.premiumbeat.com/blog/hfr-future-travel-videos/

Michelle, C., Davis, C. H., Hight, C., \& Hardy, A. L. (2015). The Hobbit hyperreality paradox. Convergence: The International Journal of Research into New Media Technologies,23(3),229-250. doi:10.1177/1354856515584880

Wilcox, L. M., Allison, R. S., Helliker, J., Dunk, B., \& Anthony, R. C. (2015). Evidence that Viewers Prefer Higher Frame-Rate Film. ACM Transactions on Applied Perception,12(4), 1-12. doi:10.1145/2810039 